\title{
New Unintended Adverse Consequences of Electronic Health Records
}

D. F. Sittig', A. Wright', J. Ash ${ }^{3}$, H. Singh ${ }^{4}$

1 University of Texas Health Science Center at Houston, School of Biomedical Informatics and UT-Memorial Hermann Center for Health Care Quality and Safety, Houston, TX, USA

2 Harvard Medical School and Brigham and Women's Hospital, Department of Medicine, Boston, MA, USA

3 Oregon Health \& Science University, Department of Medical Informatics and Clinical Epidemiology, Portland, OR, USA

4 Houston Veterans Affairs Center for Innovations in Quality, Effectiveness and Safety, Michael E. DeBakey Veterans Affairs Medical Center, Houston, Texas; and

Section of Health Services Research, Department of Medicine, Baylor College of Medicine, Houston, Texas, USA

\section{Summary}

Although the health information technology industry has made considerable progress in the design, development, implementation, and use of electronic health records (EHRS), the lofty expectations of the early pioneers have not been met. In 2006, the Provider Order Entry Team at Oregon Health \& Science University described a set of unintended adverse consequences (UACS), or unpredictable, emergent problems associated with computer-based provider order entry implementation, use, and maintenance. Many of these originally identified UACs have not been completely addressed or alleviated, some have evolved over time, and some new ones have emerged as EHRs became more widely available. The rapid increase in the adoption of EHRS, coupled with the changes in the types and attitudes of clinical users, has led to several new UACS, specifically: complete clinical information unavailable at the point of care; lack of innovations to improve system usability leading to frustrating user experiences; inadvertent disclosure of large amounts of patient-specific information; increased focus on computer-based quality measurement negatively affecting clinical workflows and patient-provider interactions; information overload from marginally useful computer-generated data; and a decline in the development and use of internally-developed EHRs. While each of these new UACs poses significant challenges to EHR developers and users alike, they also offer many opportunities. The challenge for clinical informatics researchers is to continue to refine our current systems while exploring new methods of overcoming these challenges and developing innovations to improve EHR interoperability, usability, security, functionality, clinical quality measurement, and information summarization and display.

\section{Keywords}

Electronic Health Records (EHRs), usability, confidentiality, quality indicators, data display, medical informatics

Yearb Med Inform 2016:7-12

http://dx.doi.org/10.15265/IY-2016-023

Published online November 10, 2016
Views expressed do not represent those of Department of Veterans Affairs

\section{Introduction}

Over the past 25 years, we have made significant strides in using health information technology (HIT). Many national government-led initiatives have stimulated the adoption and use of electronic health records (EHRs) around the world $[1,2,3,4]$. However, these initiatives have been met with mixed success in terms of increasing EHR adoption based on original budgets and time lines. Specifically, EHR adoption varied from $41 \%$ in Switzerland to over $98 \%$ in Norway and the Netherlands as of 2012 [5]. In the United Kingdom (UK), much of the $£ 12$ billion project [6] to promote HIT adoption was supposed to be completed by December 2010, but by then only $78 / 377$ $(21 \%)$ of the sites where implementation should have been finished had even begun the process [7]. Conversely, over the last six years, the percentage of clinicians using EHRs in the USA has increased from under $20 \%$ to well over $75 \%$, brought on mostly by the USA's $\$ 30$ billion, Health Information Technology for Economic and Clinical Health (HITECH) Act incentive program of 2009 [8].

Although we have made considerable progress, initial expectations have not been met [9]. We have not achieved what we originally envisioned [10], and there have been numerous unexpected adverse events and effects [11]. In 2006, we described a set of unintended adverse consequences (UACs) associated with the use of computer-based provider order entry (CPOE) (see Table 1) [12]. Briefly, we define UACs as unpredictable, emergent problems, associated with CPOE or EHR implementation, use, and maintenance. Many of the originally identified UACs have not been completely addressed or alleviated, and some have evolved over time (e.g., more/new work and workflow issues). Additionally, new UACs not just related to CPOE but to all aspects of EHR use have emerged. In this paper, we briefly describe these new UACs and illustrate why they must be addressed by EHR users, developers, implementers, researchers, and policy makers to help achieve the transformative effects of health information technology.

\section{Why Have New Unintended Adverse Consequences Emerged?}

The increased use of EHRs has led to a change in the types and attitudes of clinical users. As can be largely explained by Rogers' theory of the diffusion of innovations [13], "early adopters" of EHRs were mostly enthusiastic and proud to be a part of a new, innovative, and technological health care revolution. A number of these pioneering EHR users were working in academic institutions with home-grown EHRs that they developed and improved upon internally $[14,15,16,17]$. Once enough people or organizations have adopted an innovation, adoption from then 
on becomes self-sustaining. Rogers called this concept "critical mass," [13] which helps explain why there is a tipping point from which adoption becomes especially rapid [18]. However, the current "late majority" of users are different from early adopters in many ways. They use commercially available EHRs with variable and often suboptimal usability, and are much less understanding and forgiving of system limitations. In addition, during the early phases of EHR adoption, problems such as lack of interoperability and security issues remained hidden because there were not enough systems in existence outside the pioneering institutions to truly stress these systems' interoperability and security capabilities.

\section{New Types of Unintended Adverse Consequences}

Based on findings from the literature, our research projects, and field-experience from engaging with health care organizations actively developing HIT-enabled health care systems, we have witnessed several areas of concern, which we now organize into six new UACs for discussion. Knowledge was mainly gained from site visits, which included observation and interviews of key stakeholders. These visits focused on topics such as designing, developing, implementing, and evaluating clinical decision support [19]; exploration of the processes involved in identifying and communicating abnormal laboratory test results [20]; development and implementation of service-oriented clinical decision support [21]; and identification of recommended practices for ensuring safe and effective EHR implementation and use [22]. The following sections briefly describe each of these 6 new UACs along with new research opportunities and challenges they portend. We also highlight several future directions for research that need to be pursued as a direct result of these UACs.

\section{Complete Clinical Information Unavailable at the Point of Care}

One of the biggest selling points for the adoption of EHRs was the tremendous increase in availability of patients' clinical

Table 1 Previously identified unintended adverse consequences related to the use of Electronic Health Records (EHRs) by clinicians (adapted from Campbell et al. [12]).

\begin{tabular}{|l|l} 
More/new work for clinicians & $\begin{array}{l}\text { EHRs often create new work for clinical and non-clinical staff, which is most prominent at } \\
\text { the point of care (e.g., alerts, required data entry fields, and details of complex orders). } \\
\text { Enfavorable workflow issues } \\
\text { EHRs often highlight mismatches between intended and actual work processes in the } \\
\text { clinical setting by adding to previously defined ineffective or dysfunctional workflows. } \\
\text { system changes } \\
\text { Paper persistence } \\
\text { maintain the hardware infrastructure, application software, and clinical content. } \\
\text { Paper continues to be used as a temporary, portable, disposable, data input and output } \\
\text { Changes in communication } \\
\text { patterns and practices } \\
\text { medium. } \\
\text { Use of EHRs often replaces synchronous, interpersonal conversations regarding provision } \\
\text { of care with asynchronous computer-mediated messaging, often leading to an "illusion of } \\
\text { communication." } \\
\text { Specific EHR features, functions, or series of events that result in users succeeding or failing } \\
\text { in reaching their goal(s), trigger emotions that can affect their ability to carry out complex } \\
\text { physical and cognitive tasks. } \\
\text { New kinds of errors can result from problematic data presentations, confusing order options, } \\
\text { inappropriate text entries, misunderstandings related to test, training, and production } \\
\text { versions of the system, and workflow process mismatches, to name just a few. } \\
\text { Clinicians experience a loss of power or professional autonomy when EHRs prevent them } \\
\text { from ordering the types of tests or medications they prefer, or force them to comply } \\
\text { with clinical guidelines they may not embrace, or limit their narrative flexibility through } \\
\text { structured data entry. } \\
\text { Health care organizations are becoming increasingly dependent on their EHR for many } \\
\text { aspects of clinical care delivery. When the system is unavailable, chaos may ensue. }\end{array}$ \\
Changes in the power structure
\end{tabular}

data, anytime, anywhere [23]. This ubiquitous increase in data availability depended heavily on the assumption that once clinical data were routinely maintained in a computable format, they could seamlessly be transmitted, integrated, and displayed between health care systems' EHRs, regardless of differences in the developer of the EHR. Some progress has been made, for example, Epic Systems (Verona, WI) offers Care Everywhere (http://www.epic. $\mathrm{com} /$ CareEverywhere/), but it is currently limited to exchanging data between organizations in which either the sender or the receiver is using Epic's EHR, and both organizations have agreed to join the network. In addition, several other EHR developers have formed the CommonWell Alliance (http://www.commonwellalliance.org/) and are beginning to exchange data. It is obvious now that even though the majority of clinicians and health care organizations are using EHRs, complete clinical information is not yet available to them. There are a variety of reasons that unexpectedly emerged during the current rapid adoption phase including technical factors, such as incompatible data syntax, semantics, and pragmatics issues, as well as social constraints, such as data governance, ownership, and confidentiality concerns [24]. In fact, the inability to move patient data between health care organizations has given rise to a new term "information blocking" [25]. This term is used to describe some of the various socio-technical issues that often stand in the way of organizations that want to share patient information. Other issues that lead to problems in exchanging clinical information include the lack of agreement on specifications for implementing data interchange standards such as the HL7 v2.x family of standards [26] and the consolidated clinical document architecture (CCDA) [27]. While there are definitely technological challenges that limit EHR interoperability, there are also many internal, organizational, as well as external, regulatory, and socio-political challenges that also must be addressed if 
we are ever to experience true clinical and administrative information interoperability required to deliver the highest quality and lowest cost health care.

Challenges related to interoperability are a prime opportunity for clinical informatics researchers [28]. Many unanswered clinical and scientifically-important research questions are on the table, including how to aggregate, organize, reduce/transform, interpret, and synthesize information from disparate organizations across time into a concise, yet complete, clinical summary [29]; how to display these summaries of vast amounts of data in an easy to read and comprehensible format [30]; and how to develop a set of key clinical workflows that involve information exchange to be used by EHR developers to design and test their systems' features and functionality.

\section{Lack of Innovations to Improve System Usability Leads to Frustrating User Experiences}

Although EHR usability has improved considerably since the days of hard-wired, keyboard-based, VT100 terminals connected to a mainframe computer (see figure 1), very little has changed since the current mousebased, point and click, graphical user interfaces were introduced over the last 15 years. The lack of continued innovation in EHR interface design and the resulting "poor" EHR usability has only become a topic of widespread, national debate in the last 5 years [31]. Several reasons account for why this is a new concern. One, we are noticing it more substantially now as a reflection of the rapid increase in the number of new users, who are using overly complex systems, often with limited training or expertise [32]. Second, innovation in the human-computer interface, among many other facets of EHRs, has been stifled due to the rapidly changing Meaningful Use EHR certification criteria that have required EHR developers to make numerous changes to their system's user interfaces [33]. This has resulted in the dual disadvantages of increasing the complexity of these composite user interfaces while also reducing the number of people and the amount of time allocated to the

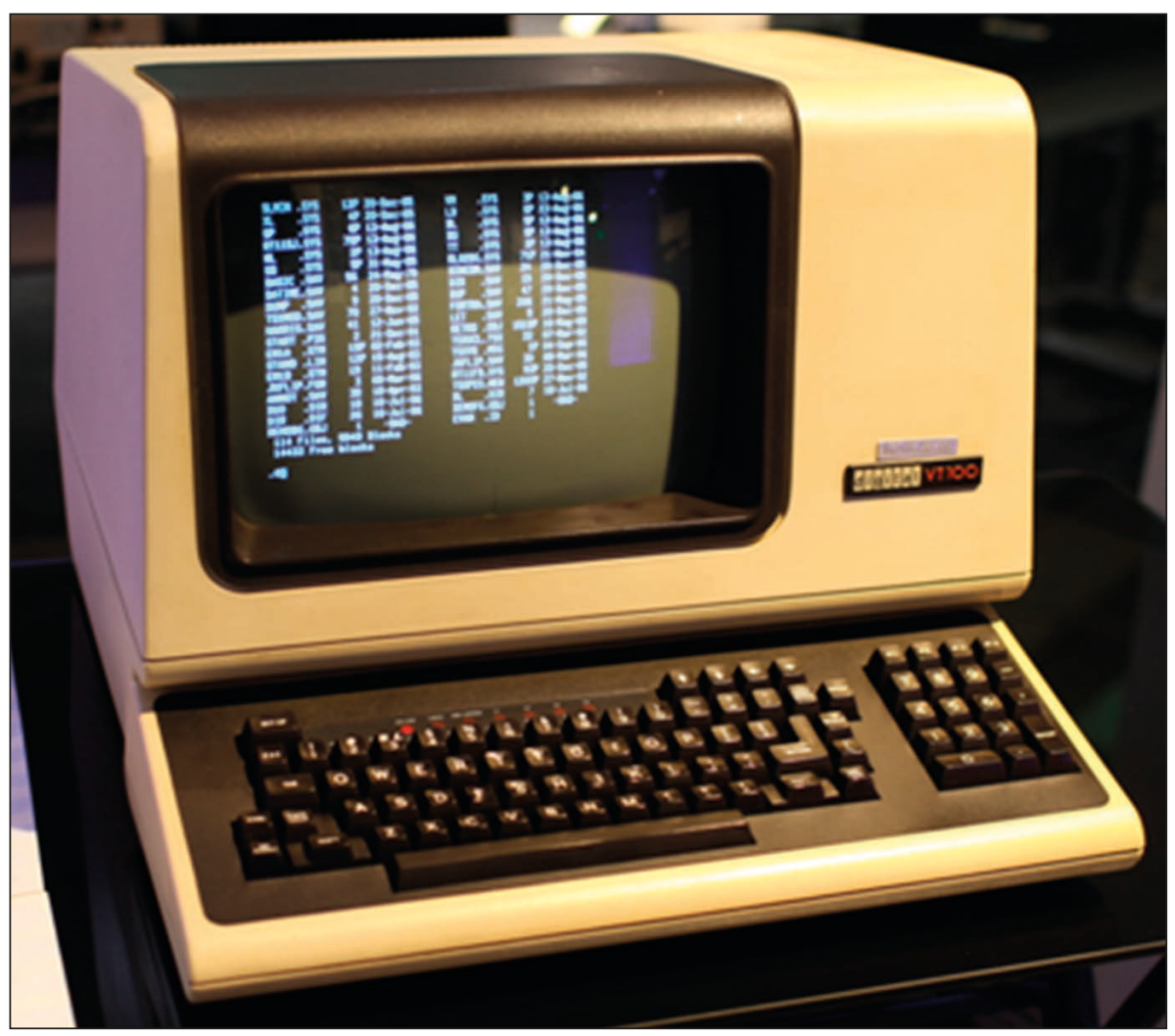

Fig. 1 A Digital Equipment Corporation (DEC) VT100 terminal. (from: https://en.wikipedia.org/wiki/User_interface)

needed system enhancements. Conversely, the recent introduction of hand-held tablet computers, with their high-resolution, multi-touch, gesture-controlled screens has significantly raised user expectations for what computer interfaces should look like and how they should behave.

These usability challenges have created many opportunities for clinical informatics and human factors researchers to better understand the clinical tasks, regulatory constraints, and capabilities of current EHRs with an eye toward the usability innovations that contribute to developing the next-generation EHR user interfaces.

\section{Inadvertent Disclosure of Large Amounts of Patient-specific Information}

Over the last several years, the health care industry has been the victim of a large number of patient privacy breaches. Some of these are the result of external bad actors trying to take advantage of the increased monetary value of personally-identifiable health-related data, such as the breach of over 78.8 million patient files at Anthem [34]. Others are the result of health care organizations' failure to take the necessary precautions to protect their systems. Many breaches have resulted from lost portable computers [35] or system backup tapes [36] that were not properly encrypted [37]. We are also beginning to experience attempts to hack various network-attached devices and change important settings [38], efforts to hold an organization's entire patient files hostage by encrypting their files [39], and denial of service attacks [40].

Such problems offer opportunities for informatics researchers. These security issues call for new methods of encrypting [41], storing [42], linking [43], and transmitting [44] protected health information. In addition, we must develop stronger policies, rules, and regulations regarding the inappropriate secondary use of identifiable health-related data $[45,46]$. 


\section{Increased Focus on Computer- based Quality Measurement Negatively Affects Clinical Workflows and Patient-provider Interactions}

The slow, but steady, move from fee-forservice to pay-for-performance payment models in health care has given rise to more EHR-based clinical quality measurement. This push for quality measurement has necessitated an increased need for capturing complete, accurate, structured data that can easily be extracted, aggregated, and reported to administrators, quality oversight organizations (e.g., University Health Consortium), and payers - both public and private. The need to capture structured data items such as "smoking status" [47], "pain scores" [48], venous thromboembolism prophylaxis, and documentation of the need for patient restraints every 24 hours has led to many convoluted clinical documentation workflows [49]. These new workflows are not only changing the way clinicians perform their work, but they are potentially interfering with their diagnostic and therapeutic critical thinking tasks leading to serious, preventable, adverse events [50], as well as having a negative impact on patient-provider interactions at the point of care [51].

However, new quality measure requirements are also creating numerous opportunities for clinical informatics researchers, including development of natural language processing methods to extract quality indicators [52]; development of new quality measure metrics [53]; and investigation of best practices for provider-computer interaction with the patient at the point of care [51].

\section{Information Overload from Marginally Useful Computer- generated Data}

As the breadth and depth of computer usage to record, store, display, and transmit clinical and administrative information have increased, so has the amount of information that clinicians are required to review and potentially act upon at the point of care. In addition to the traditional clinically-gen- erated data, over the last few years the capability for patients to generate, capture, and transmit information about various physiological (e.g., blood glucose, heart rate, or blood pressure) or physical (e.g., number of steps walked or hours slept) processes further exacerbates the amount of information potentially available for clinicians, and more recently patients, to review. In addition, the computer itself, in the form of advanced clinical decision support (e.g., drug-drug, drug-allergy, and preventive care reminders), now routinely adds to the overwhelming clutter of information that must be addressed. Many clinicians complain that they are being overwhelmed with information [54]. In addition, the ease with which clinicians can "cut and paste" information from one part of the chart, or even another patient's chart, results in "note-bloat" and obscures relevant information [55]. Also, many EHRs have the capability to "generate" text based on structured data that has been entered by clinicians. Taken together, all these new computer-readable bits of information are overwhelming clinicians and causing them to miss important information which can lead to patient harm [56].

This information overload offers clinical informaticians an unparalleled opportunity to design and develop new methods of summarizing, as well as displaying, all this new information. In addition, we must develop methods to increase the specificity of the clinical decision support suggestions presented to clinicians to reduce alert fatigue [57].

\section{Decline in the Development and Use of Internally-developed EHRs}

Over the past five years or so, the number of EHRs developed and maintained by academics for their teaching facilities, or entrepreneurs for their small practices, has declined precipitously as large academic health centers increasingly adopted commercial EHRs [58] and acquired small practices [59]. We view this rapid decline as a result of several concomitant factors. First, commercial EHR developers with their comparatively vast technical and hu- man resources, and their ability to defray their development costs across numerous clients, have for the most part duplicated the most important features and functions of internally-developed, state-of-the-art systems [60]. At the same time, these commercial systems offer health care administrators a relatively "fixed" cost for future EHR functionality [61]. Second, increasing regulatory oversight made it difficult for these internally-developed EHRs to meet the rapidly changing EHR certification requirements while also developing the new features and functions requested by their organizations and maintaining existing system functionality [62]. Finally, as small clinical practices (i.e., less than 10 physicians) began to recognize the difficulty in developing or selecting, configuring, implementing, and maintaining a state-of-the-art EHR along with the myriad of interfaces with external laboratories, hospitals to which they admit patients, referring physicians, and public health agencies, the idea of joining a local health care organization and using their commercially-developed and maintained systems became more palatable. In addition, with the relaxation of the Stark laws in the USA, hospitals were allowed to subsidize the cost of information systems [63]. Taken together, these complementary, socio-technical forces have resulted in a precipitous decline in the number of homegrown EHRs in use.

This major change in the nature of EHRs used by large organizations creates challenges but also introduces exciting new opportunities for partnerships between the academic and industry sectors [64]. For example, the development of the new HL7 FHIR (Fast Healthcare Interoperability Resources) [65] specification coupled with the SMART (Substitutable Medical Apps Reusable Technologies) [66] platform offers researchers and independent application developers the chance to create innovative apps that can be plugged in existing systems [67]. In addition, the widespread use of similar EHRs offers human factors and ethnographic researchers the opportunity to identify best practices for everything from screen design and layout [68] to organizational governance of key EHR features and functionality [69]. 


\section{Conclusions}

The health information technology revolution has already had a positive impact on the health of all citizens as well as on health care delivery systems around the world. Unfortunately, as with the application of any new technology, there have been numerous new UACs that have emerged. This is likely explained by us having reached what Rogers called the "critical mass," or tipping point , of the adoption curve [13], at which point new, different, and unanticipated problems have emerged because the numbers of users have increased so dramatically. While each of the UACs identified in this manuscript poses significant challenges to EHR developers and users alike, they offer many types of opportunities for informaticians involved in multidisciplinary research. The challenge for clinical informatics researchers is to continue to refine our current systems while exploring new methods of overcoming these challenges and developing innovations to improve EHR interoperability, usability, security, functionality, clinical quality measurement, and information summarization and display. This will involve working in partnership with both clinical operations stakeholders as well as EHR developers. The opportunities to leverage HIT to impact the health of individuals around the world have never been greater. With a focused effort that addresses UACs and facilitates a safe, effective and efficient HIT infrastructure, we can expect to see high quality and low cost health care delivered to the right person, at the right time, in the right form, leading to improved health outcomes.

\section{Acknowledgements}

Dr. Singh is supported by the VA Health Services Research and Development Service (CRE 12-033; Presidential Early Career Award for Scientists and Engineers USA 14-274), the VA National Center for Patient Safety and the Agency for Health Care Research and Quality (R01HS022087). This work is supported in part by the Houston VA HSR\&D Center for Innovations in Quality, Effectiveness and Safety (CIN 13-413).

\section{References}

1. France FR. eHealth in Belgium, a new "secure" federal network: role of patients, health professions and social security services. Int J Med Inform 2011;80:e12-6

2. Protti D, Johansen I. Widespread adoption of information technology in primary care physician offices in Denmark: a case study. Issue Brief (Commonw Fund) 2010;80:1-14. Available at: http:// www.commonwealthfund.org/ /media/Files/ Publications/Issue\%20Brief/2010/Mar/1379_Protti_widespread_adoption_IT_primary_care_Denmark_intl_ib.pdf (Accessed 1/7/2015).

3. Australian Department of Health and Ageing (DoHA). HealthConnect Evaluation. 24 August 2009. Available: http://www.health.gov.au/ internet/main/Publishing.nsf/Content/FAFD8FE999704592CA257BF00020A8CF/SFile/HealthConnect.pdf (Accessed 1/7/2016).

4. Price M, Singer A, Kim J. Adopting electronic medical records: are they just electronic paper records? Can Fam Physician 2013 Jul;59(7):e322-9.

5. Schoen C, Osborn R, Squires D, Doty M, Rasmussen $\mathrm{P}$, Pierson R, et al. A survey of primary care doctors in ten countries shows progress in use of health information technology, less in other areas. Health Aff(Millwood). 2012 Dec;31(12):2805-16.

6. House of Commons. Committee of Public Accounts. Department of Health. The National Programme for IT in the NHS. Twentieth report of session 2006-7. Report, together with formal minutes oral and written evidence. March 2007. http://www. publications.parliament.uk/pa/cm200607/cmselect/ cmpubacc/390/390.pdf (Accessed 1/7/2016)

7. Sheikh A, Cornford T, Barber N, Avery A, Takian A, Lichtner V, et al. Implementation and adoption of nationwide electronic health records in secondary care in England: final qualitative results from prospective national evaluation in "early adopter" hospitals. BMJ 2011 Oct 17;343:d6054.

8. The American Recovery and Reinvestment Act of 2009. Public Law 111-5-February 17, 2009. Pg. 227 https://www.gpo.gov/fdsys/pkg/PLAW-111publ5/ pdf/PLAW-111publ5.pdf (Accessed 22 Feb 2016)

9. Simborg DW, Detmer DE, Berner ES. The wave has finally broken: now what? J Am Med Inform Assoc 2013 Jun;20(e1):e21-5.

10. Collen MF. General requirements for a Medical Information System (MIS). Comput Biomed Res 1970 Oct 5;3(5):393-406.

11. Graber ML, Siegal D, Riah H, Johnston D, Kenyon K. Electronic Health Record-Related Events in Medical Malpractice Claims. J Patient Saf 2015 Nov 6.

12. Campbell EM, Sittig DF, Ash JS, Guappone KP, Dykstra RH. Types of unintended consequences related to computerized provider order entry. J Am Med Inform Assoc 2006 Sep-Oct;13(5):547-56.

13. Rogers, EM. Diffusion of Innovations, 5th Edition. Free Press, New York, NY; 2003.

14. McDonald CJ, Tierney WM, Overhage JM, Martin DK, Wilson GA. The Regenstrief Medical Record System: 20 years of experience in hospitals, clinics, and neighborhood health centers. MD Comput 1992 Jul-Aug;9(4):206-17.

15. Gardner RM, Pryor TA, Warner HR. The HELP hospital information system: update 1998. Int J
Med Inform 1999 Jun;54(3):169-82.

16. Miller RA, Waitman LR, Chen S, Rosenbloom ST. The anatomy of decision support during inpatient care provider order entry (CPOE): empirical observations from a decade of $\mathrm{CPOE}$ experience at Vanderbilt. J Biomed Inform 2005 Dec;38(6):469-85

17. Borst F, Appel R, Baud R, Ligier Y, Scherrer JR. Happy birthday DIOGENE: a hospital information system born 20 years ago. Int J Med Inform 1999 Jun;54(3):157-67.

18. Mennemeyer ST, Menachemi N, Rahurkar S, Ford EW. Impact of the HITECH act on physicians' adoption of electronic health records. J Am Med Inform Assoc 2015 Jul 30. pii: ocv103.

19. Wright A, Ash JS, Erickson JL, Wasserman J, Bunce A, Stanescu A, et al. A qualitative study of the activities performed by people involved in clinical decision support: recommended practices for success. J Am Med Inform Assoc. 2014 MayJun;21(3):464-72.

20. Murphy DR, Reis B, Kadiyala H, Hirani K, Sittig DF, Khan MM, et al. Electronic health record-based messages to primary care providers: valuable information or just noise? Arch Intern Med 2012 Feb 13:172(3):283-5

21. Wright A, Sittig DF, Ash JS, Erickson JL, Hickman TT, Paterno M, et al. Lessons learned from implementing service-oriented clinical decision support at four sites: A qualitative study. Int J Med Inform 2015 Nov;84(11):901-11.

22. Sittig DF, Ash JS, Singh H. The SAFER guides: empowering organizations to improve the safety and effectiveness of electronic health records. Am J Manag Care 2014 May;20(5):418-23.

23. Powsner SM, Wyatt JC, Wright P. Opportunities for and challenges of computerisation. Lancet 1998 Nov 14;352(9140):1617-22.

24. Reeve J, Hosking R, Allinson Y. Personal electronic health records: the start of a journey. Aust Prescr 2013;36:70-3. http://www.australianprescriber. com/magazine/36/3/70/3 (Accessed 1/7/2015).

25. Office of the National Coordinator for Health IT (ONC). 2015 Report to Congress on Health Information Blocking. April 2015. Available at: https://www.healthit.gov/sites/default/files/reports/ info_blocking_040915.pdf (Accessed 12/23/15).

26. HL 7 Version 2 Product Suite. Available at: http:// www.hl7.org/implement/standards/product_brief. cfm?product_id=185 (Accessed 25 Feb 2016).

27. D'Amore JD, Mandel JC, Kreda DA, Swain A, Koromia GA, Sundareswaran S, et al. Are Meaningful Use Stage 2 certified EHRs ready for interoperability? Findings from the SMART C-CDA Collaborative. J Am Med Inform Assoc. 2014 Nov-Dec;21(6):1060-8

28. Sittig DF, Wright A. What makes an EHR "open" or interoperable? J Am Med Inform Assoc 2015 Sep;22(5):1099-101.

29. Feblowitz JC, Wright A, Singh H, Samal L, Sittig DF. Summarization of clinical information: a conceptual model. J Biomed Inform 2011 Aug;44(4):688-99.

30. Wang TD, Plaisant C, Shneiderman B, Spring N, Roseman D, Marchand G, et al. Temporal summaries: supporting temporal categorical searching, aggregation and comparison. IEEE Trans Vis Comput Graph 2009 Nov-Dec;15(6):1049-56. 
31. American Medical Association. Improving Care: Priorities to Improve Electronic Health Record Usability. Available at: https://www.aace.com/files/ ehr-priorities.pdf (Accessed 12/23/15).

32. Payne TH, Corley S, Cullen TA, Gandhi TK, Harrington L, Kuperman GJ, et al. Report of the AMIA EHR-2020 Task Force on the status and future direction of EHRs. J Am Med Inform Assoc 2015 Sep;22(5):1102-10.

33. Zhang J, Walji M, editors. Better EHR: Usability, Workflow and Cognitive Support in Electronic Health Records. University of Texas School of Biomedical Informatics at Houston, TX; 2014.

34. Mathews AW. Anthem: Hacked Database Included 78.8 Million People. The Wall Street Journal, February 24, 2015. Available at: http://www.wsj. com/articles/anthem-hacked-database-included-78-8-million-people-1424807364 (Accessed $12 / 23 / 2015)$

35. Liebowitz M. Stolen laptop puts 30,000 Texas Cancer Center patients at risk. NBCNews.com June 6, 2012. Available at: http://www.nbcnews. com/id/48015851/ns/technology_and_science-security/t/stolen-laptop-puts-texas-cancer-centerpatients-risk/ (Accessed 12/23/15).

36. Merrill M. Lost TRICARE backup tapes could expose nearly 5 million records. Government Health IT, September 29, 2011. Available at: http://www. govhealthit.com/news/lost-tricare-backup-tapescould-expose-nearly-5-million-records (Accessed 12/23/15).

37. Sittig DF, Ash JS, Singh H. The SAFER guides: empowering organizations to improve the safety and effectiveness of electronic health records. Am J Manag Care 2014 May;20(5):418-23. 38. Radcliffe J. Hacking(Medical(Devices(for(Fun(and(Insulin: Breaking the Human SCADA System. Black Hat Conference August 2011. Available at: https://media.blackhat.com/bh-us-11/ Radcliffe/BH_US_11_Radcliffe_Hacking_Medical_Devices_WP.pdf (Accessed 1/4/2016).

39. Robertson J. Hackers Encrypt Health Records and Hold Data for Ransom. Bloomberg News. August 10, 2012 Available at: http://www.bloomberg.com/news/ articles/2012-08-10/hackers-encrypt-health-recordsand-hold-data-for-ransom Accessed 1/4/2016.

40. Eastwood B. How Boston Children's Hospital Hit Back at Anonymous. CIO, Sep 15, 2014. Available at: http://www.cio.com/article/2682872/healthcare/how-boston-childrens-hospital-hit-back-atanonymous.html

41. Akinyele JA, Pagano MW, Green MD, Lehmann CU, Peterson ZN, Rubin AD. Securing electronic medical records using attribute-based encryption on mobile devices. In Proceedings of the 1st ACM workshop on Security and privacy in smartphones and mobile devices 2011 Oct 17 (pp. 75-86). ACM.

42. Schweitzer EJ. Reconciliation of the cloud computing model with US federal electronic health record regulations. J Am Med Inform Assoc 2012 Mar 1;19(2):161-5.

43. Kho AN, Cashy JP, Jackson KL, Pah AR, Goel S, Boehnke J, et al. Design and implementation of a privacy preserving electronic health record linkage tool in Chicago. J Am Med Inform Assoc 2015 Sep;22(5):1072-80.

44. Zhang R, Liu L. Security models and requirements for healthcare application clouds. InCloud Com- puting (CLOUD), 2010 IEEE 3rd International Conference on $2010 \mathrm{Jul} 5$ (pp. 268-275). IEEE.

45. Willison D. Privacy and the secondary use of data for health research: experience in Canada and suggested directions forward. J Health Serv Res Policy 2003 Jul;8 Suppl 1:S1:17-23.

46. Safran C, Bloomrosen M, Hammond WE, Labkoff S, Markel-Fox S, Tang PC, et al; Expert Panel. Toward a national framework for the secondary use of health data: an American Medical Informatics Association White Paper. J Am Med Inform Assoc 2007 Jan-Feb;14(1):1-9.

47. Bowes WA 3rd. Progress and challenge in meeting meaningful use at an integrated delivery network. AMIA Annu Symp Proc 2011;2011:144-51.

48. Bramwell J. Automation Proves to Be the Right Medicine to Improve Pain Management. Leadership+Apr 16, 2012. Available at: http://www.hfma. org/Leadership/E-Bulletins/2012/April/Automation_Proves_to_Be_the_Right_Medicine_to_Improve_Pain_Management/ (Accessed 1/4/2016).

49. Cusack CM, Hripcsak G, Bloomrosen M, Rosenbloom ST, Weaver CA, Wright A, et al. The future state of clinical data capture and documentation: a report from AMIA's 2011 Policy Meeting. J Am Med Inform Assoc 2013 Jan 1;20(1):134-40. doi: 10.1136/amiajnl-2012-001093.

50. Upadhyay DK, Sittig DF, Singh H. Ebola US Patient Zero: lessons on misdiagnosis and effective use of electronic health records. Diagnosis 2014 doi: 10.1515/dx-2014-0064 Available at: http:// www.degruyter.com/view/j/dx.ahead-of-print/ dx-2014-0064/dx-2014-0064.xml

51. Street RL Jr, Liu L, Farber NJ, Chen Y, Calvitti A, Zuest D, et al. Provider interaction with the electronic health record: the effects on patient-centered communication in medical encounters. Patient Educ Couns 2014 Sep;96(3):315-9.

52. Hazlehurst BL, Kurtz SE, Masica A, Stevens VJ, McBurnie MA, Puro JE, Vijayadeva V, Au DH, Brannon ED, Sittig DF, et al. CER Hub: An informatics platform for conducting comparative effectiveness research using multi-institutional, heterogeneous, electronic clinical data. Int J Med Inform 2015 Oct;84(10):763-73.

53. Stockwell DC, Bisarya H, Classen DC, Kirkendall ES, Lachman PI, Matlow AG, et al. Development of an Electronic Pediatric All-Cause Harm Measurement Tool Using a Modified Delphi Method. J Patient Saf 2014 Aug 26.

54. Murphy DR, Reis B, Sittig DF, Singh H. Notifications received by primary care practitioners in electronic health records: a taxonomy and time analysis. Am J Med 2012 Feb;125(2):209.e1-7.

55. Partnership for Health IT Patient Safety. Health IT Safe Practices: Toolkit for the Safe Use of Copy and Paste. February 2016. Available at: https:// www.ecri.org/Resources/HIT/CP Toolkit/Toolkit_CopyPaste_final.pdf (Accessed 3/3/2016).

56. Singh H, Spitzmueller C, Petersen NJ, Sawhney MK, Smith MW, Murphy DR, et al. Primary care practitioners' views on test result management in EHR-enabled health systems: a national survey. J Am Med Inform Assoc 2013 Jul-Aug;20(4):727-35.

57. McCoy AB, Waitman LR, Lewis JB, Wright JA, Choma DP, Miller RA, Peterson JF, et al. A framework for evaluating the appropriateness of clinical decision support alerts and responses. J Am Med
Inform Assoc 2012 May-Jun;19(3):346-52.

58. Koppel R, Lehmann CU. Implications of an emerging EHR monoculture for hospitals and healthcare systems. J Am Med Inform Assoc 2015 Mar;22(2):465-71.

59. Baltic S. Monopolizing medicine: Why hospital consolidation may increase healthcare costs. February 24, 2014. Available at: medec.com/ medicinemonopoly (Accessed 1/7/2016).

60. Wright A, Sittig DF, Ash JS, Feblowitz J, Meltzer S, McMullen C, et al. Development and evaluation of a comprehensive clinical decision support taxonomy: comparison of front-end tools in commercial and internally developed electronic health record systems. J Am Med Inform Assoc 2011 May 1;18(3):232-42.

61. Buchanan J. Minnesota Data Center Sold For \$46M As Epic, Mayo Strike Another Deal. Xconomy. com January 7th, 2016. Available at: http://www. xconomy.com/wisconsin/2016/01/07/minnesotadata-center-sold-for-46m-as-epic-mayo-strikeanother-deal/ (Accessed 1/7/2016).

62. Bowes WA 3rd. Impacts of EHR Certification and Meaningful Use Implementation on an Integrated Delivery Network. AMIA Annu Symp Proc 2014 Nov 14;2014:325-32.

63. Menachemi N, Matthews M, Ford EW, Hikmet N, Brooks RG. The relationship between local hospital IT capabilities and physician EMR adoption. J Med Syst 2009 Oct;33(5):329-35.

64. Perna G. OHSU, Epic Form EHR Research and Education Collaborative. Healthcare Informatics. November 22, 2013. Available at: http://www. healthcare-informatics.com/news-item/ohsu-epic-form-ehr-research-and-education-collaborative (Accessed 1/8/2016).

65. Fast Healthcare Interoperability Resources (FHIR) Specification. Available at: https://www.hl7.org/ fhir/index.html (Accessed 1/7/2016).

66. Mandl KD, Kohane IS. No small change for the health information economy. N Engl J Med 2009 Mar 26;360(13):1278-81.

67. Klann JG, McCoy AB, Wright A, Wattanasin N, Sittig DF, Murphy SN. Health care transformation through collaboration on open-source informatics projects: integrating a medical applications platform, research data repository, and patient summarization. Interact J Med Res 2013 May 30;2(1):e11.

68. Sittig DF, Murphy DR, Smith MW, Russo E, Wright A, Singh H. Graphical display of diagnostic test results in electronic health records: a comparison of 8 systems. J Am Med Inform Assoc 2015 Jul;22(4):900-4.

69. Wright A, Sittig DF, Ash JS, Bates DW, Feblowitz J, Fraser G, et al. Governance for clinical decision support: case studies and recommended practices from leading institutions. J Am Med Inform Assoc 2011 Mar-Apr;18(2):187-94.

\section{Correspondence to:}

Dean F. Sittig

University of Texas Health Science Center at Houston

School of Biomedical Informatics

and UT-Memorial Hermann Center for Health Care Quality and Safety

Houston, Texas, USA

E-mail: Dean.F.Sittig@uth.tmc.edu 